\title{
Trends in Head and Neck Cancer in South Korea Between 1999 and 2012
}

\author{
Jeffrey D. Suh ${ }^{1}$ Jae Hoon Cho² \\ ${ }^{1}$ Department of Head and Neck Surgery, UCLA School of Medicine, Los Angeles, CA, USA; \\ ${ }^{2}$ Department of Otorhinolaryngology-Head and Neck Surgery, Konkuk University School of Medicine, Seoul, Korea
}

Objectives. The purpose is to provide detailed estimates of population-based incidences of head and neck cancers (HNCs) between 1999 and 2012 in South Korea and to evaluate trends.

Methods. Data was reviewed from the Korea National Cancer Incidence Database regarding the incidence of HNCs between 1999 and 2012. Locations that were surveyed included lip, oral tongue, oral cavity, major salivary gland, nasopharynx, nasal cavity and paranasal sinus, tonsil, hypopharynx, oropharynx, and larynx. Age-standardized incidence rates were calculated and provided with $95 \%$ confidence intervals. The increase ratio of HNCs for and male-to-female ratios were also calculated.

Results. The incidence of lip (0.07-0.10/100,000 people) and oropharyngeal cancer $(0.09-0.12 / 100,000$ people) remained low during the study period while laryngeal cancer (1.17-2.08/100,000 people) occurred most frequently. The incidence of oral tongue, major salivary gland, tonsil, and hypopharynx increased steeply compared to other HNCs between 1999 and 2012. Male-to-female ratio was over 1.0 for all HNCs, especially for those of tonsil, hypopharynx, oropharynx, and larynx cancer which were $>5.0$.

Conclusion. The incidence of all the HNCs except for laryngeal cancer has increased yearly in men and women in South Korea since 1998. Rates of oral tongue, major salivary gland, and tonsil cancer have increased the most rapidly during this time period.

Keywords. Head and Neck Neoplasms; Incidence; Republic of Korea

\section{INTRODUCTION}

Head and neck cancer (HNC) encompasses a heterogenous group of malignancies involving multiple sites including the oral cavity, pharynx, larynx, paranasal sinuses, and neck. The relative frequency of HNC is very low compared to other sites such as the lung and colon $[1,2]$, however, HNC draws enormous attention because of potentially devastating consequences on quality

\footnotetext{
- Received July 10, 2015

Revised September 17, 2015

Accepted December 29, 2015

- Corresponding author: Jae Hoon Cho

Department of Otorhinolaryngology-Head and Neck Surgery, Konkuk

University Medical Center, Konkuk University School of Medicine, 120-1

Neungdong-ro, Gwangjin-gu, Seoul 05030, Korea

Tel: +82-2-2030-7667, Fax: +82-2-2030-5299

E-mail: jaehoon@kuh.ac.kr
}

of life [3,4].Tobacco use remains the most important risk factor for HNC, followed by alcohol consumption [4]. In general, longterm use of both tobacco and alcohol account for the most cases of HNC. Recently, human papilloma virus has been found to play an important role in carcinogenesis, especially in HNC involving the tonsil, base of the tongue, and other parts of the pharynx [4-6].

Prior studies have reported on the worldwide incidence of HNC [1,2,7-16]. The type and frequency of HNC often varies considerably by region and country $[1,2]$, likely due to ethnic and genetic differences, smoking and alcohol consumption habits, and occupational and environmental exposures [1,2,4]. In 1999, the Korean government launched The Korea National Cancer Incidence Database, recognizing the importance of systematic and comprehensive management of patients with cancer. By law, all hospitals in South Korea must report each new

Copyright @ 2016 by Korean Society of Otorhinolaryngology-Head and Neck Surgery.

This is an open-access article distributed under the terms of the Creative Commons Attribution Non-Commercial License (http://creativecommons.org/licenses/by-nc/4.0)

which permits unrestricted non-commercial use, distribution, and reproduction in any medium, provided the original work is properly cited. 
cancer diagnosis to Korea Central Cancer Registry Center, which manages and analyzes the data. This registry provides a powerful tool to better understand the incidence and trends of HNC in Korea, much like the Surveillance, Epidemiology, and End Results tumor registry in the United States.

The objective of this study was to provide detailed estimates of population-based incidences of HNC between 1999 and 2012 in Korea and to evaluate cancer trends.

\section{MATERIALS AND METHODS}

\section{Cancer registration and population data}

A retrospective study was performed using The Korean National Cancer Incidence Database. Institutional review board approval was not required for this deidentified registry. The Korean National Cancer Incidence database codes information regarding the primary site and extent of disease. All patients diagnosed with HNCs from 1999 to 2012 were identified using site-specific codes defined below.

\section{Definition of HNCs}

Sites of HNC (identified by International Classification of Diseases code, 10th version) were reviewed from the database and included in this study included: lip (C00), oral tongue (C01, 02), oral cavity (C03-06), major salivary gland $(\mathrm{C} 07,08)$, nasopharynx (C11), nasal cavity and paranasal sinus (C30, 31), tonsil (C09), hypopharynx $(\mathrm{C} 12,13)$, oropharynx (C10), and larynx (C32). Oral tongue was defined separately from oral cavity, and tonsil from oropharynx. Thyroid cancer was not included in this study as it had been recently evaluated elsewhere. Cancer type and association with human papilloma virus (HPV) were not considered for this study.

\section{Statistical analysis}

Average of age-standardized incidence rates during 1999 to 2012 were calculated and provided with $95 \%$ confidence intervals for each tumor site. The increase ratio of HNCs for were also calculated. We defined it as ratio of average incidence number during 2009-2011 to 1999-2001. Because the value of age-

\section{H I}

- Head and neck cancer (HNC) trends were estimated from the Korea National Cancer Database between 1999 and 2012.

- Incidence of HNCs remained low in the lip and oropharynx but high in the larynx.

- Incidence of HNCs steeply increased in the oral tongue, major salivary gland, tonsil, and hypopharynx.

- Male-to-female was high (>5.0) in tonsil, hypopharynx, oropharynx, and larynx cancer. standardized incidence rate of HNCs was too small for the calculation, we used the incidence number instead. Total population of Korea was 46,136,000 at 2000 and increased to $48,580,000$ at 2010 , which means the population grew roughly $5.3 \%$ during 2000-2010. Therefore, we included this population increase in our calculations when comparing the incidence number in 2000 and 2010.

Population-adjusted ratio $=$ average cancer incidence number from 2009-2011/average incidence number from 1999$2001 \times 1.053$

Male-to-female incidence ratios were also calculated by using the average incidence number during 1999-2001 and 20092011, respectively. We divided the average incidence number of male population by those of female population at same period and compared the ratios between 1999-2001 and 2009-2011 to investigate any potential trends in male-to-female ratio.

\section{RESULTS}

Average age-standardized incidence rate per 100,000 during 1999 to 2012

Table 1 shows the average age-standardized incidence rate per 100,000 of Korea during 1999 to 2012. Incidence rates of lip (0.07-0.10/100,000 people) and oropharyngeal cancer (0.09$0.12 / 100,000$ people) were very low while laryngeal cancer occurred most frequently among HNCs (1.17-2.08/100,000 people).

\section{Cancer trends from 1999-2012}

Fig. 1 illustrates trends in HNC from1999-2012 in South Korea. The incidence of oral tongue, major salivary gland, tonsil, and hypopharynx increased steeply compared to other HNCs during this time period. Increase ratios of HNCs for 10 years ranged from 1.00 (for laryngeal cancer) to 2.34 (for tonsil cancer). The increase ratios for 10 years of all HNCs except laryngeal cancer (1.00) and lip cancer (1.02) were over 1.10. The difference of increase ratios between two genders were great (over 0.3 ) for tonsil, hypopharynx, and larynx cancer, which means that the male incidence of HNCs has been increased more steeply than female incidence for those HNCs. Especially for laryngeal cancer, the increase ratio was 1.04 for male, while only 0.64 for female. This data is summarized in Table 2.

\section{Male-to-female ratio}

Male-to-female ratio was over 1.0 for all HNCs. Tonsil, hypopharynx, oropharynx, and larynx cancers had a ratio of $>5.0$, signifying a heavy predominance of these cancers in Korean men. Comparing the ratios between 1999-2001 and 20092011, those of nasopharyngeal cancer (2.44 to 1.31 ) decreased 
Table 1. Average age-standardized incidence rate per 100,000 of head and neck cancer during 1999 to 2012 in Korea

\begin{tabular}{lcccc}
\hline Primary site & ICD-10 ${ }^{\text {a) }}$ Code & Total & Male & Female \\
\hline Lip & $\mathrm{C} 00$ & $0.07-0.10$ & $0.10-0.10$ & $0.00-0.04$ \\
Oral tongue & $\mathrm{C} 01,02$ & $0.72-0.80$ & $1.07-1.18$ & $0.42-0.51$ \\
Oral cavity ${ }^{\text {b) }}$ & $\mathrm{C} 03-06$ & $0.71-0.92$ & $1.09-1.40$ & $0.41-0.58$ \\
Major salivary gland & $\mathrm{C} 07,08$ & $0.54-0.64$ & $0.66-0.76$ & $0.45-0.56$ \\
Nasopharynx & $\mathrm{C} 11$ & $0.62-0.68$ & $0.96-1.03$ & $0.31-0.36$ \\
Nasal cavity and paranasal sinus & $\mathrm{C} 30,31$ & $0.48-0.52$ & $0.67-0.73$ & $0.32-0.37$ \\
Tonsil & $\mathrm{C} 09$ & $0.36-0.46$ & $0.66-0.84$ & $0.10-0.13$ \\
Hypopharynx & $\mathrm{C} 12,13$ & $0.54-0.59$ & $1.17-1.26$ & $0.07-0.10$ \\
Oropharynx ${ }^{c)}$ & $\mathrm{C} 10$ & $0.09-0.12$ & $0.22-0.29$ & $0.00-0.00$ \\
Larynx & $\mathrm{C} 32$ & $1.75-2.08$ & $3.71-4.38$ & $0.21-0.29$ \\
\hline
\end{tabular}

Values are presented as $95 \%$ confidence interval.

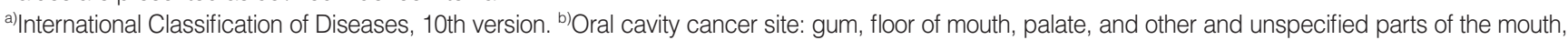
except for oral tongue. ${ }^{c)}$ Oropharyngeal cancer sites: base of tongue, lingual tonsil, pharynx not otherwise specified, and Waldeyer ring, except for tonsil.
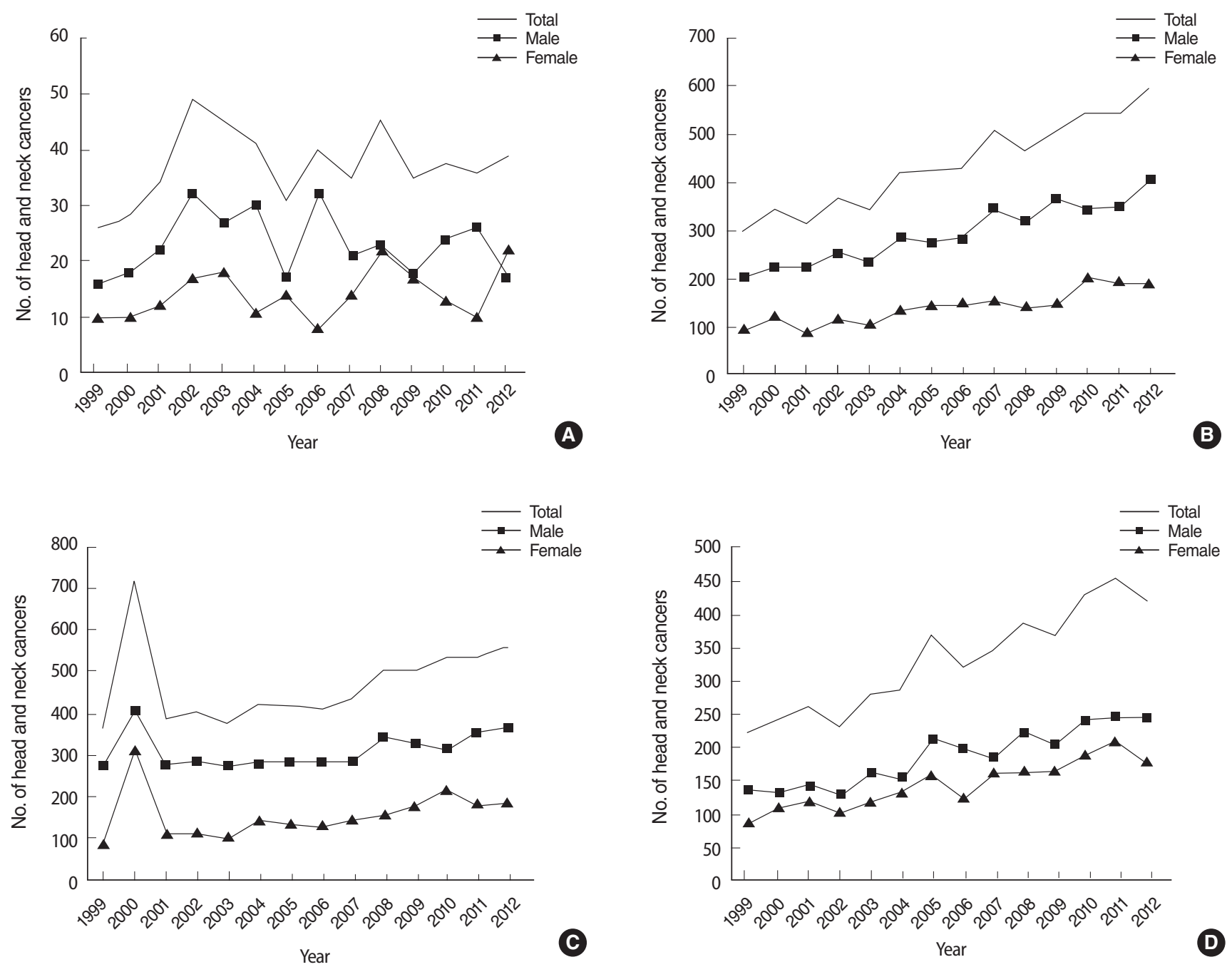

Fig. 1. Trend of incidence number of head and neck cancers in Korea from 1999 to 2012. (A) Lip, (B) oral tongue, (C) oral cavity, (D) major salivary gland. 

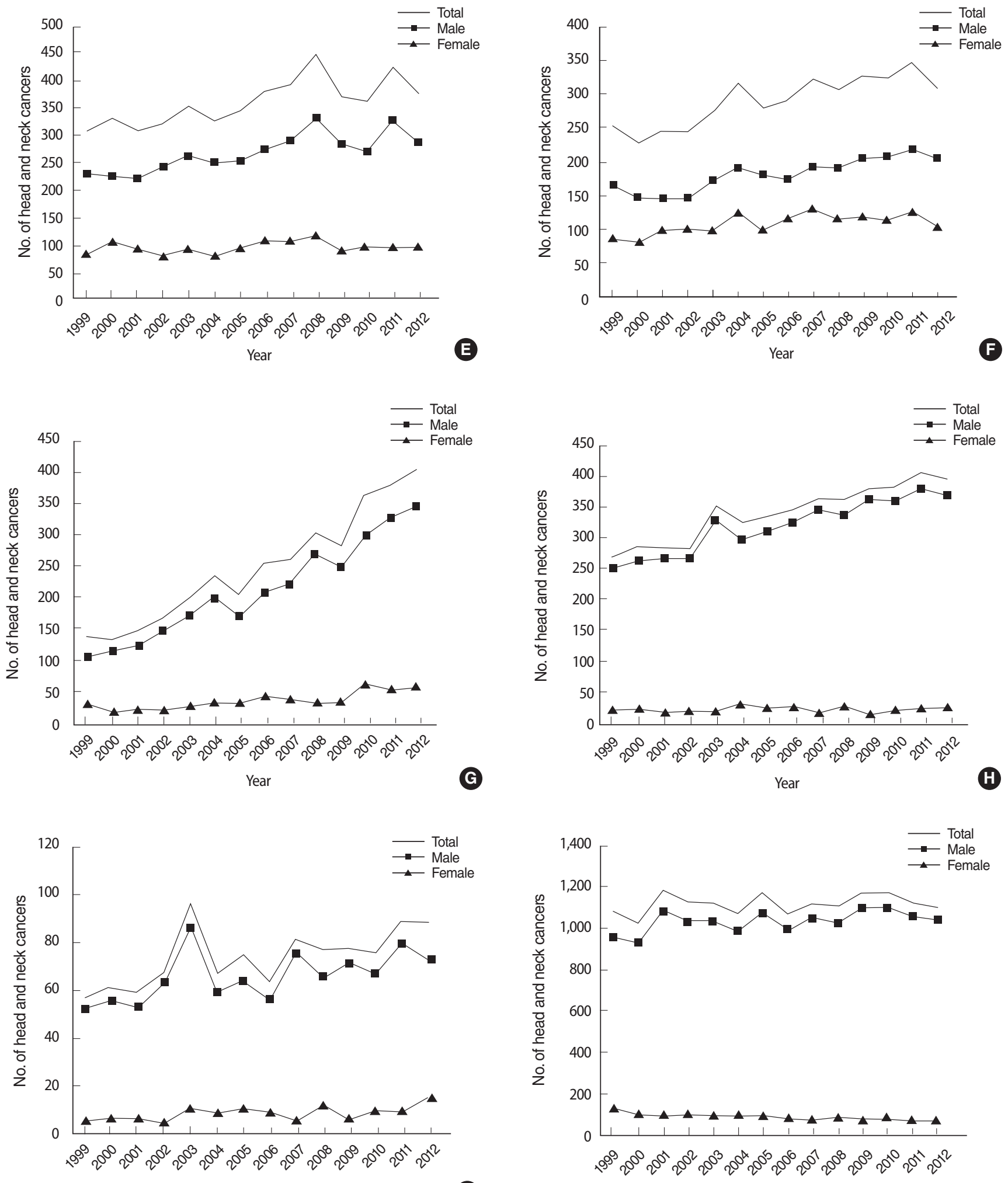

Year

(1)

Year

(1)

Fig. 1. Continued. (E) nasopharynx, (F) nasal cavity/paransal sinus, (G) tonsil, (H) hypopharynx, (I) oropharynx, and (J) larynx. 
Table 2. Comparison of average incidence numbers of head and neck cancer between 1999-2001 and 2009-2011

\begin{tabular}{|c|c|c|c|c|c|c|c|c|c|}
\hline \multirow{2}{*}{ Primary site } & \multicolumn{3}{|c|}{ Average incidence no. (1999-2001) } & \multicolumn{3}{|c|}{ Average incidence no. (2009-2011) } & \multicolumn{3}{|c|}{ Increase ratio of incidence no. ${ }^{\text {a) }}$} \\
\hline & Total & Male & Female & Total & Male & Female & Total & Male & Female \\
\hline Lip & 29.3 & 18.7 & 10.7 & 36.0 & 22.7 & 13.3 & 1.17 & 1.15 & 1.19 \\
\hline Oral tongue & 321.3 & 218.7 & 102.7 & 535.7 & 354.3 & 181.3 & 1.59 & 1.54 & 1.68 \\
\hline Oral cavity & 491.0 & 319.7 & 171.3 & 526.0 & 333.3 & 192.7 & 1.02 & 0.99 & 1.06 \\
\hline Major salivary gland & 243.0 & 137.3 & 105.7 & 418.0 & 230.7 & 187.3 & 1.63 & 1.60 & 1.68 \\
\hline Nasopharynx & 315.3 & 223.7 & 91.7 & 384.3 & 292.3 & 92.0 & 1.16 & 1.24 & 0.95 \\
\hline Nasal cavity and paranasal sinus & 241.0 & 152.0 & 89.0 & 327.7 & 209.7 & 118.0 & 1.29 & 1.31 & 1.26 \\
\hline Tonsil & 138.7 & 115.7 & 23.0 & 341.7 & 291.7 & 50.0 & 2.34 & 2.39 & 2.06 \\
\hline Hypopharynx & 279.3 & 260.3 & 19.0 & 387.0 & 367.0 & 20.0 & 1.32 & 1.34 & 1.00 \\
\hline Oropharynx & 59.0 & 53.3 & 5.7 & 80.3 & 72.3 & 8.0 & 1.29 & 1.29 & 1.34 \\
\hline Larynx & $1,092.7$ & 989.0 & 103.7 & $1,151.3$ & $1,081.7$ & 69.7 & 1.00 & 1.04 & 0.64 \\
\hline
\end{tabular}

a)Population growth-adjusted ratio: average incidence number during 2009-2011/(average incidence no. during 1999-2001×1.053).

Table 3. Comparison of male to female ratio of head and neck cancer from 1999-2001 to 2009-2011

\begin{tabular}{lcc}
\hline \multirow{2}{*}{ Primary site } & \multicolumn{2}{c}{$\begin{array}{c}\text { Male to female ratio of average } \\
\text { incidence no. }\end{array}$} \\
\cline { 2 - 3 } & $1999-2001$ & 2009-2011 \\
\hline Lip & 1.75 & 1.70 \\
Oral tongue & 2.13 & 1.95 \\
Oral cavity & 1.87 & 1.73 \\
Major salivary gland & 1.30 & 1.23 \\
Nasopharynx & 2.44 & 1.31 \\
Nasal cavity and paranasal sinus & 1.71 & 1.38 \\
Tonsil & 5.03 & 5.83 \\
Hypopharynx & 13.70 & 18.35 \\
Oropharynx & 9.41 & 9.04 \\
Larynx & 9.54 & 15.53 \\
\hline
\end{tabular}

substantially, while those of hypopharynx (13.70 to 18.35$)$ and larynx cancers (9.54 to 15.53) became much greater. This data is summarized in Table 3.

\section{DISCUSSION}

The incidence of HNCs can vary considerably by country and gender $[1,2,4]$. According to an international comparison study by Simard et al. [1], the incidence of oral cavity cancer increased among both genders in some European countries, remained stable in a number of Asian countries, and decreased in Canada and the United States. In this study, the incidence of oropharyngeal cancer increased among both genders in eastern, some northern European nations, and some Asian countries, while declined in China and India [1]. For laryngeal cancers, incidence and trends varied by sex in other areas [1]. The exact reason for these differences are not fully understood, however differences in the level of consumption of tobacco and alcohol are believed to be the main reason [4].
The prevalence of smoking among Korean adults is very high, especially for men. According to the data of the Korea National Statistical Office, the prevalence of smoking was $66.3 \%$ for men and $6.5 \%$ for women in 1998 , since then continuously decreased to $42.1 \%$ for men and $6.2 \%$ for women in 2013 . Jee et al. [17] reported some data in which consumption amount of tobacco increased steeply from mid-1950's to mid-1990's in South Korea and lung cancer mortality started to increase with similar proportion from 1980. The authors argued that the effect of smoking on lung cancer statistics would appear decades later due to a lag period between the exposure and the onset of disease [17]. The effects of smoking would results in similar trends of HNCs in Korea. Saito el al. [18] found that smoking over 40 years is poor prognostic factor for oropharyngeal cancer.A study by International Agency for Research on Cancer also reported that the relative risk for laryngeal cancer was greater than 10 for subjects who had smoked for greater than 40 years [19]. Therefore we can assume that the lag period between smoking exposure and the incidence of some HNCs is approximately 40 years. Considering this data, we could infer that the incidence of some HNCs in Korea will continue to increase until the mid2030's when considering decreased rates of tobacco use in the county.

Our data also illustrates that the incidence of all HNCs except laryngeal cancer increased from 1998 to 2012. The prevalence of smoking among Korean women did not vary much between 1998 and 2013, ranging from $5.2 \%$ to $7.4 \%$. Our data found that the incidence of all HNCs for men outnumbered those for women significantly (male-to-female ratio, 1.23 to 18.35). However, the rates over 10 years did not show much change between men and women except in regards to laryngeal cancer (1.04 for men and 0.64 for women). For oral tongue, oral cavity, oral salivary gland, and oropharynx cancers, the rates of increase were greater among women than men. We have no specific explanation for this finding, except an increasing prevalence of women smoking during mid-1950's to mid-1990's. 
Alcohol is also well-known risk factor for HNCs even though the effect is much smaller than tobacco [4]. Heavy drinking is not uncommon in Korea for both men and women. The prevalence of heavy alcohol use for men over the last 10 years is $24.9 \%$, and $6.8 \%$ for women. According to World Health Organization [20], the annual amount of hard liquor consumption per person over 15 years is 9.57 liters in Korea, which is the highest of all surveyed countries. We did not have data about alcohol consumption in the Korean database, but we presume that alcohol use likely played an important role in the incidence of HNC in Korea, independently or synergistically with tobacco.

HPV also likely plays a role in the incidence of HNCs in Korea. The exact rate of oral infection with HPV is unknown, however, one study on Korean mothers and their neonates reported that HPV was detected in cervix of 72 among 469 pregnant women $(15.4 \%)$ and in the mouth of 15 neonates $(3.2 \%)$, with a rate of vertical transmission of $20.8 \%$ [21]. Another study based on Korean patients showed that the HPV was detected in $36 \%$ (13 of 36) of oral tongue cancer patients, compared with $4 \%$ ( 1 of 25 ) of normal controls [22]. Considering this data, we can infer that HPV likely contributes to the incidence of HNCs in Korea. Our study also showed that over the last 10 years the incidence for oral tongue (1.67 times) and tonsil cancers (2.46 times) increased rapidly compared to cancers of other HNCs. For laryngeal cancer, which is not known to be strongly associated with this virus, the incidence rate was stable for men (1.04 times) and even dropped steeply for women (0.64 times).

In conclusion, the incidence of all the HNCs except for laryngeal cancer has steadily increased for both men and women in Korea since 1998. Among the different types of HNC, oral tongue, major salivary gland, and tonsil cancer have seen the most rapid increase. Cancer in Korean males is higher than females for all types of HNCs, especially for cancer of the tonsil, hypopharynx, oropharynx, and larynx.

\section{CONFLICT OF INTEREST}

No potential conflict of interest relevant to this article was reported.

\section{AKNOWLEDGMENTS}

This study was supported by Konkuk University, Seoul, Republic of Korea.

\section{REFERENCES}

1. Simard EP,Torre LA, Jemal A. International trends in head and neck cancer incidence rates: differences by country, sex and anatomic site.
Oral Oncol. 2014 May;50(5):387-403.

2. Chaturvedi AK, Anderson WF, Lortet-Tieulent J, Curado MP, Ferlay $\mathrm{J}$, Franceschi S, et al. Worldwide trends in incidence rates for oral cavity and oropharyngeal cancers. J Clin Oncol. 2013 Dec;31(36): 4550-9.

3. Van Nieuwenhuizen AJ, Buffart LM, Brug J, Leemans CR, Verdonckde Leeuw IM. The association between health related quality of life and survival in patients with head and neck cancer: a systematic review. Oral Oncol. 2015 Jan;51(1):1-11.

4. Argiris A, Karamouzis MV, Raben D, Ferris RL. Head and neck cancer. Lancet. 2008 May;371(9625):1695-709.

5. Hwang TZ, Hsiao JR, Tsai CR, Chang JS. Incidence trends of human papillomavirus-related head and neck cancer in Taiwan, 1995-2009. Int J Cancer. 2015 Jul;137(2):395-408.

6. Stein AP, Saha S, Yu M, Kimple RJ, Lambert PF. Prevalence of human papillomavirus in oropharyngeal squamous cell carcinoma in the United States across time. Chem Res Toxicol. 2014 Apr;27(4): 462-9.

7. Ioka A,Tsukuma H,AjikiW, Oshima A. Trends in head and neck cancer incidence in Japan during 1965-1999. Jpn J Clin Oncol. 2005 Jan;35(1):45-7.

8. ZnaorT,Vucemilo L, Kulis T, Znaor A. Incidence and mortality trends of head and neck cancer in Croatia in the period 1988-2008. Acta Otolaryngol. 2013 Mar;133(3):305-12.

9. Siddiqui MS, Chandra R, Aziz A, Suman S. Epidemiology and histopathological spectrum of head and neck cancers in Bihar, a state of Eastern India. Asian Pac J Cancer Prev. 2012;13(8):3949-53.

10. Patel SC, CarpenterWR, Tyree S, Couch ME, Weissler M, Hackman T, et al. Increasing incidence of oral tongue squamous cell carcinoma in young white women, age 18 to 44 years. J Clin Oncol. 2011 Apr; 29(11):1488-94.

11. Guntinas-Lichius O, Wendt T, Buentzel J, Esser D, Lochner P, Mueller A, et al. Head and neck cancer in Germany: a site-specific analysis of survival of the Thuringian cancer registration database. J Cancer Res Clin Oncol. 2010 Jan;136(1):55-63.

12. Braakhuis BJ,Visser O, Leemans CR. Oral and oropharyngeal cancer in The Netherlands between 1989 and 2006: increasing incidence, but not in young adults. Oral Oncol. 2009 Sep;45(9):e85-9.

13. Doobaree IU, Landis SH, Linklater KM, El-Hariry I, Moller H, Tyczynski J. Head and neck cancer in South East England between 1995-1999 and 2000-2004: an estimation of incidence and distribution by site, stage and histological type. Oral Oncol. 2009 Sep;45(9): 809-14.

14. Chen K, Song F, He M, Li H, Qian B, Zhang W, et al.Trends in head and neck cancer incidence in Tianjin, China, between 1981 and 2002. Head Neck. 2009 Feb;31(2):175-82.

15. Yeole BB. Trends in incidence of head and neck cancers in India. Asian Pac J Cancer Prev. 2007 Oct-Dec;8(4):607-12.

16. Carvalho AL, Nishimoto IN, Califano JA, Kowalski LP. Trends in incidence and prognosis for head and neck cancer in the United States: a site-specific analysis of the SEER database. Int J Cancer. 2005 May;114(5):806-16.

17. Jee SH, Kim IS, Suh I, Shin D, Appel LJ. Projected mortality from lung cancer in South Korea, 1980-2004. Int J Epidemiol. 1998 Jun; 27(3):365-9.

18. Saito N, Sairenchi T, Irie F, Iso H, Iimura K, Watanabe H, et al. Duration of cigarette smoking is a risk factor for oropharyngeal cancer mortality among Japanese men and women: the Ibaraki Prefectural Health Study (IPHS). Ann Epidemiol. 2013 Sep;23(9):546-50.

19. IARC Working Group on the Evaluation of Carcinogenic Risks to Humans. Tobacco smoke and involuntary smoking. IARC Monogr Eval Carcinog Risks Hum. 2004;83:1-1438.

20. World Health Organization. World health statistics 2013. Geneva: World Health Organization; 2013. 
21. Hahn HS, Kee MK, Kim HJ, Kim MY, Kang YS, Park JS, et al. Distribution of maternal and infant human papillomavirus: risk factors associated with vertical transmission. Eur J Obstet Gynecol Reprod Biol. 2013 Jul;169(2):202-6.
22. Lee SY, Cho NH, Choi EC, Baek SJ, Kim WS, Shin DH, et al. Relevance of human papilloma virus (HPV) infection to carcinogenesis of oral tongue cancer. Int J Oral Maxillofac Surg. 2010 Jul;39(7): 678-83. 